\title{
Efficacy and Safety of Bevacizumab-Combined Chemotherapy for Advanced and Recurrent Endometrial Cancer: A Systematic Review and Meta-analysis
}

\author{
Hui Chen $₫$, Minglin Liang $₫$, Jie Min $(\mathbb{0}$
}

Department of Obstetrics and Gynecology, Union Hospital, Tongji Medical College, Huazhong University of Science and Technology, Wuhan, China

Background: Bevacizumab-combined chemotherapy is a new regimen for advanced/recurrent endometrial cancer.

Aims: To evaluate the efficacy and safety of bevacizumab-combined chemotherapy in advanced/recurrent endometrial cancer.

Study design: Systematic review and meta-analysis.

Methods: Eligible studies were retrieved from Embase, PubMed, and Cochrane Library. The data of primary outcomes including progression-free survival and overall survival and secondary outcomes including overall survival, response rate, and adverse events (grade $\geq 2$ ) were extracted, pooled, and used for the meta-analysis to compare the efficacy and safety of bevacizumab-combined chemotherapy with other treatments in patients with advanced/recurrent endometrial cancer.

Results: Notably, 2 randomized-controlled and 5 single-arm trials of bevacizumab-combined chemotherapy or bevacizumab single-agent therapy for endometrial cancer were included. Meta-analysis indicated that bevacizumab-combined chemotherapy significantly increased the progression-free survival rate (hazard ratio $=0.82,95 \%$ confidence interval $=0.70,0.97$ ) and overall survival rate (hazard ratio $=0.83,95 \%$ confidence interval $=0.70,0.98$ ) compared with chemotherapy alone. The rates of overall, complete, and partial response to bevacizumab-combined chemotherapy were $76 \%, 22 \%$, and $21 \%$, respectively. The 6 and 12-month disease-free progression rates after bevacizumab-combined chemotherapy were $79 \%$ and $62 \%$, respectively. Anemia (23\%), leukopenia (46\%), neutropenia (51\%), hypertension (16\%), and fatigue $(24 \%)$ were the general adverse events after bevacizumab-combined chemotherapy.

Conclusion: Bevacizumab-combined chemotherapy may have a higher efficacy in improving the overall and progression-free survival in patients with advanced/recurrent endometrial cancers compared with chemotherapy alone.
Endometrial cancer is the most common gynecological tumor and one of the leading causes of cancer-related deaths in women $(1,2)$. Patients with advanced (the International Federation of Gynecology and Obstetrics stages III-IV) or recurrent endometrial cancers always have a dismal prognosis, and the conventional chemotherapy is not ideal for this cohort.

Paclitaxel and carboplatin (PC) chemotherapy is a standard therapy for advanced and recurrent endometrial cancer (3-5). According to recent randomized-controlled trials (RCTs), the combination of PC with bevacizumab showed significant benefits in endometrial cancer $(3,4)$. Lorusso et al. (3) showed that the median overall survival (OS) and progression-free survival (PFS) for patients with advanced or recurrent endometrial cancers receiving PC chemo- therapy were 29.7 and 10.5 months, respectively. They indicated the combination of PC plus bevacizumab had a median OS of 40.0 months and a median PFS of 13.7 months. In addition, the PC chemotherapy combined with bevacizumab achieved a higher overall response rate $(74.4 \%)$ than $\mathrm{PC}$ chemotherapy (53.1\%). Aghajanian et al. (4) and Rose et al. (5) also confirmed the beneficial effect of bevacizumab-combined chemotherapy in endometrial cancer.

Bevacizumab is a recombinant humanized monoclonal antibody against vascular endothelial growth factor (VEGF) A, which is expressed in most endometrial cancers especially in advanced types (6-8). However, the higher incidence of grade $\geq 2$ adverse events including hypertension and arterial and venous thrombosis might query the safety of bevacizumab-combined chemotherapy in endo-

Address for Correspondence: Jie Min, Department of Obstetrics and Gynecology, Union Hospital, Tongji Medical College, Huazhong University of Science and Technology, Wuhan, China e-mail: WHXHJY126@163.com

Received: April 17, 2020 Accepted: October 30, $2020 \cdot$ DOI: 10.5152/balkanmedj.2021.20121

Available at www.balkanmedicaljournal.org

ORCID iDs of the authors: H.C. 0000-0002-7540-1576; M.L. 0000-0002-0887-906X; J.M. 0000-0002-6931-138X.

Cite this article as:

Chen H, Liang M, Min J. Efficacy and Safety of Bevacizumab-Combined Chemotherapy for Advanced and Recurrent Endometrial Cancer: A Systematic Review and Meta-analysis. Balkan Med J 2021;38:7-12

Copyright@Author(s) - Available online at http://balkanmedicaljournal.org/ 
metrial cancer $(3,4)$. Accordingly, bevacizumab-combined therapy for endometrial cancer is still controversial.

Therefore, we performed this systematic review and meta-analysis to analyze the efficacy and safety of bevacizumab-combined therapy for advanced or recurrent endometrial cancers. Single-arm trials or RCTs were included and used for the analysis.

\section{MATERIALS AND METHODS}

\section{Ethics statement}

This systematic review and meta-analysis was designed and performed following the Preferred Reporting Items for Systematic Reviews and Meta-analyses protocols (9). Human samples and animals were not included in this study, and therein, ethics committee approval is inapplicable. The International Prospective Register of Systematic Reviews registration number of this study is CRD42020206474.

\section{Search strategy}

We systematically searched the English publications updated to December 2019 in the PubMed, Embase, and the Cochrane Library. Publications were searched using the searching terms of "endometrial cancer," "Endometrial carcinoma," "Bevacizumab," and "Avastin." The searching strategy was "endometrial cancer[Title/Abstract]" OR "endometrial cancer[MeSH Terms]" OR "Endometrial carcinoma[Title/Abstract]" OR "Endometrial carcinoma[MeSH Terms]" AND "Bevacizumab [MeSH Terms]" OR "Bevacizumab [Title/Abstract]" OR "Avastin [Title/Abstract]" OR "Avastin [MeSH Terms]" AND "randomized controlled trial [MeSH]" OR "random allocation [MeSH]" OR "[ singl* OR doubl* OR trebl* OR tripl*] AND [blind* OR mask*]."

\section{Inclusion and exclusion criteria for eligible reports}

The inclusion criteria were: (1) clinical trials with and without control group design; (2) English articles involving adult patients (aged $\geq 18$ years) with endometrial cancer, without age and ethnicity restriction; (3) patients treated with chemotherapy combined with bevacizumab; (4) at least 2 outcomes such as OS, PFS, objective response rate (ORR), and adverse events (grade $\geq 2$ ), among others. Reports were excluded if they were: (1) duplicated articles; (2) without the aforementioned outcomes; (3) reviews or case reports.

\section{Outcome measures and data extraction}

Full-text articles were retrieved and the title, first author name, publication year, number of patients, age of patients, and outcome data were extracted. The primary outcome was PFS and the secondary outcomes were OS, ORR, complete response rate (CRR), partial response rate (PRR), and adverse events. Outcome data were extracted and assessed independently by 2 authors (Chen $\mathrm{H}$ and Min J).

\section{Evaluation of quality}

The 5-point Jadad scoring tool (10) and methodological index for nonrandomized studies (11) were used for the assessment of RCTs and nonrandomized studies, respectively. RCTs with scores $\geq 3$ and nonrandomized studies with scores $\geq 10$ were regarded as high-quality reports; RCTs with scores $\leq 2$ and nonrandomized studies with scores $<10$ were considered as low-quality reports. The secondary review was performed in case of doubt. The evidence strength of outcome data was evaluated using the commonly used Cochrane Collaboration Grade Profiler (GradePro; McMaster University and Evidence Prime Inc. . All right reserved. McMaster University, Hamilton, Ontário, Canada) tool (http://ims.cochrane. org). Accordingly, publication bias was assessed for the included reports based on the key elements of bias risk assessment.

\section{Statistical analysis}

Meta-analysis was performed using the Stata software (StataCorp LLC, College Station, TX; version 15.1) and RevMan 5.2 (Cochrane, London, UK). Data heterogeneity was evaluated using the $\chi^{2}$ test and $I^{2}$ statistics, with a threshold of $\mathrm{p}<0.10$. Homogeneity data $\left(I^{2}<50 \%\right)$ were pooled and analyzed using a fixed-effects model, and heterogeneity data $\left(I^{2} \geq 50 \%\right)$ were pooled and analyzed using a random-effects model. Effect size or hazard ratio (HR) and 95\% confidence intervals (CIs) were calculated for all analyses. The inverse variance and Mantel-Haenszel method were used for the meta-analysis for continuous and dichotomous variables, respectively. $\mathrm{p}<0.05$ was considered as apparent difference.

\section{RESULTS}

\section{Study identification}

We searched 742 studies in databases (including 317 in PubMed, 398 in Embase, and 27 in Cochrane Library). After removing the duplicates ( $\mathrm{n}=293), 449$ articles were titles and abstracts screened by 2 authors. The remaining 17 studies were full-text screened, and 7 articles $(3-5,12-15)$ were finally included in this study according to the inclusion criteria. The flowchart of the search strategy followed is shown in Figure 1.

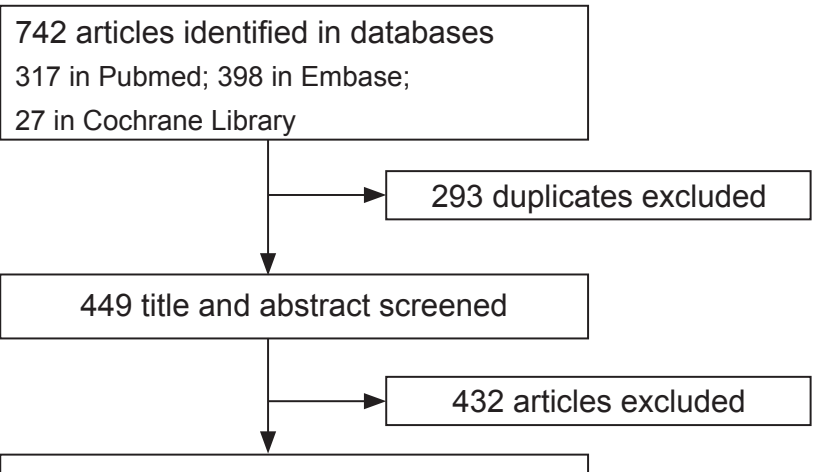

17 full-texts screening

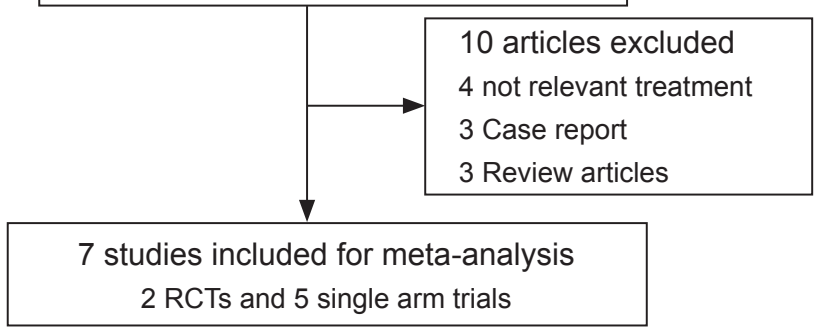

FIG. 1. The PRISMA flowchart of search strategy followed for article search and selection in this study. Notably, 7 studies were included in this systematic review, including 2 RCTs and 5 single-arm trials. PRISMA: Preferred Reporting Items for Systematic Reviews and Meta-analyses, RCTs: randomized-controlled trials. 
TABLE 1. Demographic characteristics of the included studies

\begin{tabular}{|c|c|c|c|c|c|c|c|c|c|c|}
\hline \multirow[b]{2}{*}{ Author, year } & \multirow[b]{2}{*}{ Region } & \multirow[b]{2}{*}{ Phase } & \multirow[b]{2}{*}{ Design } & \multirow{2}{*}{$\begin{array}{l}\text { Patient number } \\
(\mathrm{Com} / \mathrm{C})\end{array}$} & \multirow[b]{2}{*}{ Age $(y, \mathrm{Com} / \mathrm{C})$} & \multicolumn{2}{|c|}{ Interventions } & \multirow{2}{*}{$\begin{array}{l}\text { Median } \\
\text { OS (mo) }\end{array}$} & \multirow[b]{2}{*}{ Outcomes } & \multirow{2}{*}{$\begin{array}{l}\text { Jadad/ } \\
\text { MINORS }\end{array}$} \\
\hline & & & & & & Com & $\mathrm{C}$ & & & \\
\hline $\begin{array}{l}\text { Lorusso D, } \\
2019 \text { (3) }\end{array}$ & Italy & II & $\mathrm{RCT}$ & $54 / 54$ & $\begin{array}{l}63(28,81) / 65 \\
(32,80)\end{array}$ & $\begin{array}{l}\text { Bevacizumab plus } \\
\text { PC }\end{array}$ & $\mathrm{PC}$ & 23.5 & $\begin{array}{l}\text { OS, PFS, } \\
\text { ORR, CPR, } \\
\text { PRR, AEs }\end{array}$ & 5 \\
\hline $\begin{array}{l}\text { Aghajanian C, } \\
2018 \text { (4) }\end{array}$ & USA & II & $\mathrm{RCT}$ & $116 / 118 / 115$ & $\begin{array}{l}62(36,87) / 65 \\
(37,89) / 63(38,82)\end{array}$ & $\begin{array}{l}\text { Bevacizumab plus } \\
\text { PC; ixabepilone } \\
\text { plus carboplatin plus } \\
\text { bevacizumab }\end{array}$ & $\begin{array}{l}\text { PC plus } \\
\text { temsirolimus }\end{array}$ & 36 & $\begin{array}{l}\text { OS, PFS, } \\
\text { ORR, AEs }\end{array}$ & 4 \\
\hline $\begin{array}{l}\text { Rose PG, } \\
2017 \text { (5) }\end{array}$ & USA & II & ST & 34 & $62(32,88)$ & $\begin{array}{l}\text { Bevacizumab plus } \\
\text { PC }\end{array}$ & None & 56 & $\begin{array}{l}\text { OS, PFS, } \\
\text { ORR, CPR, } \\
\text { PRR, AEs }\end{array}$ & 14 \\
\hline $\begin{array}{l}\text { Alvarez E, } \\
2013 \text { (12) }\end{array}$ & USA & II & ST & 53 & $63(35,80)$ & $\begin{array}{l}\text { Bevacizumab plus } \\
\text { temsirolimus }\end{array}$ & None & 16.9 & $\begin{array}{l}\text { OS, PFS, } \\
\text { ORR, CPR, } \\
\text { PRR, AEs }\end{array}$ & 13 \\
\hline $\begin{array}{l}\text { Aghajanian C, } \\
2011 \text { (13) }\end{array}$ & USA & II & ST & 52 & $62(32,84)$ & Bevacizumab & None & 10.55 & $\begin{array}{l}\text { OS, PFS, } \\
\text { ORR, CPR, } \\
\text { PRR, AEs }\end{array}$ & 14 \\
\hline $\begin{array}{l}\text { Simpkins F, } \\
2015 \text { (14) }\end{array}$ & USA & II & ST & 15 & $63(32,88)$ & $\begin{array}{l}\text { Bevacizumab plus } \\
\text { PC }\end{array}$ & None & 58 & $\begin{array}{l}\text { OS, PFS, } \\
\text { ORR, CPR, } \\
\text { PRR, AEs }\end{array}$ & 12 \\
\hline $\begin{array}{l}\text { Wright JD, } \\
2007 \text { (15) }\end{array}$ & USA & NA & ST & 11 & $57(38,70)$ & $\begin{array}{l}\text { Bevacizumab plus } \\
\text { cytotoxic }\end{array}$ & None & 15.3 & $\begin{array}{l}\text { OS, PFS, } \\
\text { ORR, PRR, } \\
\text { AEs }\end{array}$ & 12 \\
\hline
\end{tabular}

AEs: adverse events, ORR: overall response rate, CPR: complete response rate, PRR: partial response rate, OS: overall survival, PC: paclitaxel plus carboplatin, PFS: progression-free survival, RCT: randomized-controlled trial, ST: single-arm trial, NA: not applicable, Com: experiment group (PC combined), C: control group; MINORS: methodological index for nonrandomized studies

\section{Study characteristics}

The 7 studies included 2 RCTs $(3,4)$ and 5 non-RCTs $(5,12-15)$ and 622 patients with advanced and recurrent or persistent endometrial cancers. In the trials published since $2015(3-5,14)$, patients were mainly treated with PC chemotherapy combined with bevacizumab, whereas in that published before 2015, patients were treated with bevacizumab alone (13) or in combination with other cytotoxic agents including temsirolimus, paclitaxel, 5-fluorouracil, cyclophosphamide, doxorubicin, and carboplatin plus docetaxel (12-15). The outcomes including OS, PFS, ORR, PRR, and/or adverse events (grade of $\geq 2$ ) were reported in all trials (Table 1). There was no risk of bias across the included studies (Figure S1).

\section{Median progression-free survival and overall survival}

Notably, 3 studies (3-5) involving 491 patients with advanced endometrial cancers reported the median PFS and OS at $>12$ months after therapy. The pooled data of PFS $\left(I^{2}=0 \%, \mathrm{p}=0.54\right)$ and OS $\left(I^{2}=17 \%, \mathrm{p}=0.31\right)$ were homogeneity. Meta-analysis showed there were significant differences in PFS $(\mathrm{HR}=0.82,95 \% \mathrm{CI}=0.70$, 0.97, $\mathrm{p}=0.02$ ) (Figure 2a) and $\mathrm{OS}(\mathrm{HR}=0.83,95 \% \mathrm{CI}=0.70,0.98$, $\mathrm{p}=0.03$ ) (Figure $2 \mathrm{~b}$ ) between patients receiving chemotherapy combined with $(n=307)$ and without bevacizumab $(n=184)$. Aghajanian et al. (4) also suggested a significantly increased OS at 36 months in patients treated with PC chemotherapy combined with bevacizumab $(\mathrm{n}=116 ; \mathrm{HR}=0.71,92.2 \% \mathrm{CI}=0.55,0.91)$, but not in patients treated with ixabepilone-carboplatin chemotherapy combined with bevacizumab $(\mathrm{n}=118$; $\mathrm{HR}=0.99,92.2 \% \mathrm{CI}=0.77,1.23)$. However, Aghajanian et al. (4) showed that there was no signifi- cant difference in PFS between patients receiving PC chemotherapy combined with and without bevacizumab $(\mathrm{HR}=0.81,92.2 \%$ $\mathrm{CI}=0.63,1.02)$.

\section{Response rate}

The ORR, CRR, and PRR ranged from 53\% to $74.4 \%(3,4), 1.9 \%$ to $44.7 \%(3,12-14)$, and $11.0 \%$ to $40 \%(3,5,12-15)$, respectively, in the included studies. Aghajanian et al. (4) indicated the ORRs after bevacizumab-combined chemotherapy were $59 \%$ and $53 \%$, and Lorusso et al. (3) reported that there was a high ORR of 74.4\% in patients receiving bevacizumab-combined chemotherapy. Meta-analysis showed that bevacizumab-combined chemotherapy induced a pooled ORR (3 studies, 172/233), CRR (5 studies, 43/201), and PRR (6 studies, 59/212) of 76\% (95\% CI=71\%, 81\%; fixed-effects model, $I^{2}=0 \%, \mathrm{p}=0.887$ ) (Figure $\left.\mathrm{S} 2 \mathrm{a}\right), 22 \%$ (95\% CI=9\%, $35 \%$; random-effects model, $I^{2}=93.5 \%, \mathrm{p}<0.001$ ) (Figure $\mathrm{S} 2 \mathrm{~b}$ ), and $21 \%\left(95 \% \mathrm{CI}=16 \%, 26 \%\right.$; fixed-effects model, $I^{2}=49.1 \%$, p=0.080) (Figure S2c), respectively.

\section{Rate of stable disease and tumor progression}

The rates of stable disease and tumor progression in patients with endometrial cancers ranged from $11.8 \%$ to $55.1 \%(3,5,12,14,15)$ and $2.9 \%$ to $45.5 \%(3,5,14,15)$, respectively. The pooled stable disease (6 studies, 73/212) and tumor progression rates (4 studies, 9/107) were 33\% (95\% CI=19\%, 47\%; random-effects model, $\left.I^{2}=79.6 \%, \mathrm{p}<0.001\right)($ Figure S3a) and 7\% (95\% CI=1\%, 17\%; random-effects model, $I^{2}=61.8 \%, \mathrm{p}=0.049$ ) (Figure $\mathrm{S} 3 \mathrm{~b}$ ), respectively. The non-progression rates of disease at 6 and 12 months were $79 \%$ 
a

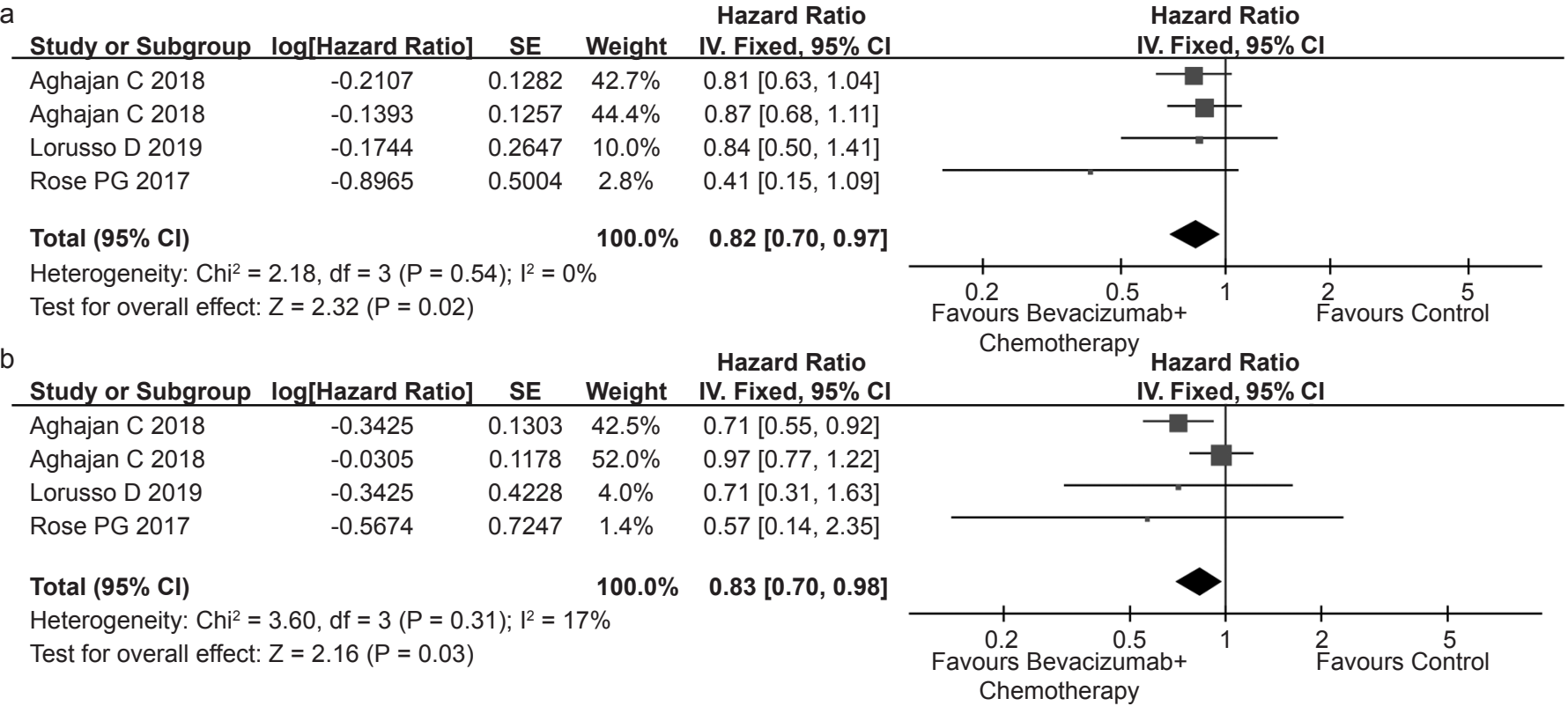

FIG. 2. a, b. The forest plot of the pooled median PFS and OS in patients treated with bevacizumab-combined chemotherapy. The forest plot evaluating the efficacy of chemotherapy plus bevacizumab in improving the PFS and OS in patients with endometrial cancers $(n=491)(a$ and $b)$. The difference level was calculated using the inverse variance (IV) method. SE: standard error, Cl: confidence interval, PFS: progression-free survival, OS: overall survival.

TABLE 2. The common adverse events in patients with endometrial cancers after bevacizumab combined with chemotherapy

\begin{tabular}{|c|c|c|c|c|c|}
\hline Adverse events (grade $\geq 2$ ) & ES & $95 \% \mathrm{CI}$ & Model & $\mathrm{I} 2$ & $\mathrm{p}$ \\
\hline Anemia & $23 \%$ & $14 \%, 33 \%$ & Random-effects & $83.4 \%$ & $<0.0001$ \\
\hline Leukopenia & $46 \%$ & $26 \%, 65 \%$ & Random-effects & $85.3 \%$ & $<0.0001$ \\
\hline Neutropenia & $51 \%$ & $30 \%, 73 \%$ & Random-effects & $96.4 \%$ & $<0.0001$ \\
\hline Thrombocytopenia & $16 \%$ & $9 \%, 23 \%$ & Random-effects & $71.0 \%$ & 0.002 \\
\hline Hypertension & $16 \%$ & $12 \%, 20 \%$ & Fixed-effects & 0 & 0.899 \\
\hline Pain $($ grade $\geq 2$ ) & $20 \%$ & $8 \%, 31 \%$ & Random-effects & $72 \%$ & 0.013 \\
\hline Fatigue & $24 \%$ & $12 \%, 36 \%$ & Fixed-effects & 0 & 0.817 \\
\hline Arterial thromboembolic events & $1 \%$ & $0 \%, 2 \%$ & Fixed-effects & 0 & 0.871 \\
\hline Venous thromboembolic events & $8 \%$ & $5 \%, 11 \%$ & Fixed-effects & 0 & 0.999 \\
\hline Fistulas & $3 \%$ & $1 \%, 5 \%$ & Fixed-effects & 0 & 0.770 \\
\hline Dyspnea & $5 \%$ & $1 \%, 10 \%$ & Fixed-effects & $41.5 \%$ & 0.191 \\
\hline Nausea & $3 \%$ & $1 \%, 6 \%$ & Fixed-effects & $10.7 \%$ & 0.345 \\
\hline Hemorrhage & $3 \%$ & $0 \%, 6 \%$ & Fixed-effects & 0 & 0.543 \\
\hline
\end{tabular}

ES: effect size, CI: confidential interval; p value indicates the $\chi 2$ test for the data heterogeneity $\left(I^{2}\right)$

$\left(95 \% \mathrm{CI}=68 \%, 90 \%\right.$; random-effects model, $\left.I^{2}=89.6 \%, \mathrm{p}<0.001\right)$

(Figure S4A) and 62\% (95\% CI=57\%, 68\%; $\left.I^{2}=18.0 \%, \mathrm{p}=0.301\right)$

(Figure $\mathrm{S} 4 \mathrm{~b}$ ), respectively.

\section{Adverse events}

The common grade $\geq 2$ adverse events after bevacizumab-combined chemotherapy were anemia $(23 \%, 95 \% \mathrm{CI}=14 \%, 33 \%)(\mathrm{Ta}-$ ble 2), leukopenia $(46 \%, 95 \% \mathrm{CI}=26 \%, 65 \%)$, neutropenia $(51 \%$, $95 \% \mathrm{CI}=30 \%, 73 \%)$, thrombocytopenia $(16 \%, 95 \% \mathrm{CI}=9 \%, 23 \%)$, hypertension $(16 \%, 95 \% \mathrm{CI}=12 \%, 20 \%$ ), pain (grade $\geq 2 ; 20 \%$, $95 \% \mathrm{CI}=8 \%, 31 \%)$, and fatigue $(24 \%, 95 \% \mathrm{CI}=12 \%, 36 \%)$. The infrequent adverse events were arterial thromboembolic events $(1 \%, 95 \% \mathrm{CI}=0 \%, 2 \%)$, nausea $(3 \%, 95 \% \mathrm{CI}=1 \%, 6 \%)$, venous thromboembolic events $(8 \%, 95 \% \mathrm{CI}=5 \%, 11 \%)$, fistulas $(3 \%$, $95 \% \mathrm{CI}=1 \%, 5 \%)$, dyspnea $(5 \%, 95 \% \mathrm{CI}=1 \%, 10 \%)$, and hemorrhage $(3 \%, 95 \% \mathrm{CI}=0 \%, 6 \%)$ (Table 2$)$.

\section{DISCUSSION}

VEGFs are important proteins in angiogenesis and nourishing and supplying oxygen to tumors $(7,16)$. It has been reported that VEGFs express a higher level in metastatic and advanced tumors 
$(7,8,17,18)$. Some researchers indicated that the addition of bevacizumab into the standard or conventional chemotherapy strategies improved the survival time in patients with advanced cancers (3, $4)$. In addition, there is a large gap in the ORR between clinical trials, ranging from $13.5 \%$ to $82.8 \%(3-5)$. This meta-analysis of trials (5 single-arms and 2 RCTs) demonstrated that the OS and PFS in patients with advanced/recurrent endometrial cancers were increased by bevacizumab-combined chemotherapy compared with control, with a high ORR of $76 \%(95 \% \mathrm{CI}=71 \%, 81 \%)$. The rate of grade $\geq 2$ adverse events was relatively high: leukopenia, $46 \%$; neutropenia, $51 \%$; and fatigue, $24 \%$.

VEGF is associated with a higher histological grade, metastasis, and invasion of several malignant cancers $(8,14,19)$. VEGF-mediated signaling pathways are critical to feature cancer stem cells, tumorigenesis, and self-renewal of cancer stem cells (20). By contrast, anti-VEGF therapy using bevacizumab could reduce the expression level of plasma VEGF (21) and the tumor volume in a preclinical orthotopic mouse model of endometrial cancer (22). Bevacizumab has been approved for the first-line treatment of advanced colorectal cancer in 2004 (23, 24). Aghajanian et al. (4) enrolled a large cohort of 349 patients assigned into 3 arms and showed that there was a significant increase in OS at 36 months in patients treated with PC chemotherapy combined with bevacizumab compared with the historical reference arm. Simpkins et al. (14) reported that $93 \%$ of patients were progression-free at 6 months after a median treatment period of 8 causes. Lorusso et al. (3) showed that the addition of bevacizumab to $\mathrm{PC}$ chemotherapy improved the OS from 29.7 months to 40.0 months compared with PC chemotherapy $(\mathrm{HR}=0.71, \mathrm{p}=0.24)$. Our meta-analysis involving 3 trials showed that the OS and PFS at $>12$ months were increased significantly by bevacizumab-combined chemotherapy, with an ORR, CRR, and PRR of $76 \%, 22 \%$, and $21 \%$, respectively. The $6-$ and 12 -month PFS were $79 \%$ and $62 \%$, respectively. These findings suggested that bevacizumab-combined chemotherapy may have a high efficacy in advanced/recurrent endometrial cancer.

The biggest problem related to bevacizumab-combined chemotherapy was high incidence of grade $\geq 2$ adverse events. Bevacizumab was associated with the high incidences of mild and severe events including bleeding, neutropenia, and nonhematological toxicity like arterial and venous thrombosis and hypertension $(3,4,8)$. The incidence of adverse events after bevacizumab-combined chemotherapy in the study by Aghajanian et al. (4) was $100 \%$ in the 3 groups, and the incidences of grade $\geq 3$ adverse events were $93.7 \%$, $98.2 \%$, and $95.6 \%$ in the PC plus bevacizumab, PC plus temsirolimus, and ixabepilone plus carboplatin plus bevacizumab groups. Lorusso et al. (3) reported that patients in the PC plus bevacizumab group had a higher incidence of grade $\geq 3$ adverse events $(n=92)$ in 53 patients, and patients $(n=53)$ in the control PC chemotherapy group developed 51 grade $\geq 3$ adverse events. Our present study showed the common adverse events after bevacizumab-combined chemotherapy were anemia (23\%), leukopenia (46\%), neutropenia $(51 \%)$, thrombocytopenia (16\%), hypertension $(16 \%)$, pain $(20 \%)$, and fatigue $(24 \%)$, and adverse events including arterial $(1 \%)$ and venous thromboembolic events $(8 \%)$, dyspnea $(5 \%)$, and hemorrhage $(3 \%)$ were rare. These findings were in consistent with the results of other studies $(25,26)$.
Lorusso et al. (3) and Aghajanian et al. (4) both indicated that the appearance of grade $\geq 2$ or 3 hypertension was higher after the inclusion of bevacizumab than control therapies. The rate of hypertension was relatively low and was lower than that in patients with other cancers receiving bevacizumab $(27,28)$. Shah et al. (27) and Zhu et al. (28) performed a meta-analysis and showed that the incidence of hypertension was significantly and dose-dependently increased among patients receiving bevacizumab. The reason for the increased incidence of hypertension was unclear and was assumed to be associated with the renin-angiotensin-aldosterone system and the production of angiotensin II derived from renin-mediated conversion (25). The frequent monitoring of blood pressure is recommended for patients receiving bevacizumab-combined chemotherapy.

The limitations in this study included: (1) various treatment cycles among the included trials; (2) small patient sizes; and (3) non-uniform regimes of bevacizumab-combined chemotherapy. For instance, Aghajanian et al. (13) treated 56 patients with $>1$ to 8 cycles of single-agent bevacizumab; Alvarez et al. (12) treated 53 patients with 1 to 19 cycles of bevacizumab combined with temsirolimus; Aghajanian et al. (4) treated 116 patients with PC combined with bevacizumab and 115 patients with ixabepilone plus carboplatin combined with bevacizumab for 6 to 8 cycles; and Lorusso et al. (3) treated 54 patients with 6 to 8 cycles of PC therapy combined with bevacizumab. The efficacy and safety of using bevacizumab as a combined or adjuvant chemotherapy for advanced/recurrent endometrial cancers may be clearer after overcoming these problems.

This study showed that conventional chemotherapy combined with bevacizumab had a potential efficacy in improving the OS and PFS in patients with advanced/recurrent endometrial cancers. The ORR, CRR, and PRR in patients after bevacizumab-combined chemotherapy were $76 \%, 22 \%$, and $21 \%$, respectively, with a high incidence of adverse events, including leukopenia, neutropenia, hypertension, and anemia. The 6- and 12-month PFS in patients receiving bevacizumab-combined chemotherapy were $79 \%$ and $62 \%$, respectively. This systematic review and meta-analysis of 7 clinical trials suggested that bevacizumab-combined chemotherapy may have a higher efficacy in patients with advanced/recurrent endometrial cancer than chemotherapy alone. However, the safety of it is inconclusive.

Ethics Committee Approval: Since it was a systematic review, its approval to the ethics committee was not required. However, this systematic review and meta-analysis was registered in an international database (PROSPERO, CRD42020206474).

Patient Consent for Publication: N/A.

Data-Sharing statement: N/A.

Author Contributions: Concept - H.C., J.M.; Design - H.C.; Supervision - J.M.; Resources - H.C.; Materials - H.C., J.M.; Data Collection and/or Processing - H.C., J.M.; Analysis and/or Interpretation - H.C., M.L.; Literature Search - H.C.; Writing Manuscript - H.C.; Critical Review - J.M., M.L.

Conflict of Interest: The authors have no conflicts of interest to declare.

Funding: The authors declared that this study has received no financial support. 


\section{REFERENCES}

1. Marcus D, Savage A, Balog J, Kudo H, Abda J, Dina R, et al. P74 Endometrial cancer: Can the iKnife diagnose endometrial cancer? Int J Gynecol Cancer 2019;29:A100-A101. [Crossref]

2. Morice P, Leary A, Creutzberg C, Abu-Rustum N, Darai E. Endometrial cancer. The Lancet 2016;387:1094-108. [Crossref]

3. Lorusso D, Ferrandina G, Colombo N, Pignata S, Pietragalla A, Sonetto C, et al. Carboplatin-paclitaxel compared to carboplatin-paclitaxel-bevacizumab in advanced or recurrent endometrial Cancer: MITO END-2-A randomized phase II trial. Gynecol Oncol 2019;155:406-12. [Crossref]

4. Aghajanian C, Filiaci V, Dizon DS, Carlson JW, Powell MA, Alvarez Secord A, et al. A Phase II Study of frontline paclitaxel/carboplatin/bevacizumab, paclitaxel/carboplatin/temsirolimus, or ixabepilone/carboplatin/bevacizumab in advanced/recurrent endometrial cancer. Gynecol Oncol 2018;150:274-81. [Crossref]

5. Rose PG, Ali S, Moslemi-Kebria M, Simpkins F. Paclitaxel, carboplatin, and bevacizumab in advanced and recurrent endometrial carcinoma. Int J Gynecol Cancer 2017;27:452-58. [Crossref]

6. Hirai M, Nakagawara A, Oosaki T, Hayashi Y, Hirono M, Yoshihara T. Expression of vascular endothelial growth factors (VEGF-A/VEGF-1 and VEGF-C/VEGF-2) in postmenopausal uterine endometrial carcinoma. Gynecol Oncol 2001;80:181-8. [Crossref]

7. Dziobek K, Opławski M, Grabarek BO, Zmarzły N, Tomala B, Halski T, et al. Changes in the expression profile of VEGF-A, VEGF-B, VEGFR-1, VEGFR-2 in Different Grades of Endometrial Cancer. Curr Pharm Biotechnol 2019;20:955-63. [Crossref]

8. Miles D, Cameron D, Hilton M, Garcia J, O'Shaughnessy J. Overall survival in MERiDiAN, a double-blind placebo-controlled Randomised Phase III trial evaluating first-line bevacizumab plus paclitaxel for HER2-negative metastatic breast cancer. Eur J Cancer 2018;90:153-5. [Crossref]

9. Moher D, Liberati A, Tetzlaff J, Altman DG, PRISMA Group. Preferred reporting items for systematic reviews and meta-analyses: The PRISMA statement. PLoS Med 2009;18:e123. [Crossref]

10. Jadad AR, Moore RA, Carroll D, Jenkinson C, Reynolds DJM, DJG Phil, et al. Assessing the quality of reports of randomized clinical trials: Is blinding necessary? Control Clin Trials 1996;17:1-12. [Crossref]

11. Slim K, Nini E, Forestier D, Kwiatkowski F, Panis Y, Chipponi J. Methodological index for non-randomized studies (MINORS): Development and validation of a new instrument. Anz Journal of Surgery 2003;73:712-6. [Crossref]

12. Alvarez E, Brady W, Walker J, Rotmensch J, Zhou X, Kendrick J, et al. Phase II trial of combination bevacizumab and temsirolimus in the treatment of recurrent or persistent endometrial carcinoma: A Gynecologic Oncology Group Study. Gynecol Oncol 2012;125:S17. [Crossref]

13. Aghajanian C, Sill MW, Darcy KM, Greer B, McMeekin DS, Rose PG, et al. Phase II trial of bevacizumab in recurrent or persistent endometrial cancer: A Gynecologic Oncology Group Study. J Clin Oncol 2011;29:2259-65. [Crossref]
14. Simpkins F, Drake R, Escobar PF, Nutter B, Rasool N, Rose PG. A Phase II Trial of Paclitaxel, Carboplatin, and Bevacizumab in Advanced and Recurrent Endometrial Carcinoma (EMCA). Gynecol Oncol 2015;136:240-5. [Crossref]

15. Wright JD, Powell MA, Rader JS, Mutch DG, Gibb RK. Bevacizumab therapy in patients with recurrent uterine neoplasms. Anticancer Res 2007;27:3525-8.

16. Hua F, Tian Y. CCL4 Promotes the Cell Proliferation, invasion and migration of endometrial carcinoma by targeting the VEGF-A signal pathway. Int J Clin Exp Pathol 2017; 10:11288-99.

17. Sopo M, Anttila M, Hämäläinen K, Kivelä A, Ylä-Herttuala S, Kosma VM, et al Expression Profiles of VEGF-A, VEGF-D and VEGFR1 Are Higher in Distant Metastases Than in Matched Primary High Grade Epithelial Ovarian Cancer. BMC Cancer 2019;19:584. [Crossref]

18. Macedo F, Ladeira K, Longatto-Filho A, Martins SF. Gastric Cancer and Angiogenesis: Is VEGF A Useful Biomarker to Assess Progression and Remission? J Gastric Cancer 2017;17:1-10. [Crossref]

19. Frezzetti D, Gallo M, Maiello MR, D'Alessio A, Esposito C, Chicchinelli N, et al VEGF as A Potential Target in Lung Cancer. Expert Opin Ther Targets 2017;21:95966. [Crossref]

20. Mercurio AM. VEGF/Neuropilin Signaling in Cancer Stem Cells. Int J Mol Sci 2019;20:490. [Crossref]

21. Jampol LM, Glassman AR, Liu D, Aiello LP, Bressler NM, Duh EJ, et al. Plasma VEGF Concentrations after Intravitreous Anti-VEGF Therapy for Diabetic Macular Edema. Ophthalmology 2018;125:1054-63. [Crossref]

22. Davies S, Dai D, Pickett G, Thiel KW, Korovkina VP, Leslieet KK. Effects of bevacizumab in mouse model of endometrial cancer: Defining the molecular basis for resistance. Oncol Rep 2011;25:855-62. [Crossref]

23. Muhsin M, Graham J, Kirkpatrick P. Bevacizumab. Nat Rev Drug Discov 2004;3:9956. [Crossref]

24. Meyerhardt JA, Li L, Sanoff HK, Carpenter 4th W, Schrag D. Effectiveness of bevacizumab with first-line combination chemotherapy for medicare patients with stage IV colorectal cancer. J Clin Oncol 2012;30:608-15. [Crossref]

25. Shord SS, Bressler LR, Tierney LA, Cuellar S, George A. Understanding and managing the possible adverse effects associated with bevacizumab. Am J Health Syst Pharm 2009;66:999-1013. [Crossref]

26. von Pawel J, Spigel DR, Ervin T, Losonczy G, Barlesi F, Juhász E, et al. Randomized Phase II Trial of Parsatuzumab (Anti-EGFL7) or Placebo in Combination with Carboplatin, Paclitaxel, and Bevacizumab for First-Line Nonsquamous Non-Small Cell Lung Cancer. Oncologist 2018;23:654-e58. [Crossref]

27. Shah MK, Shah MA, Shah SD. Risk of Hypertension with Bevacizumab, An Antibody Against Vascular Endothelial Growth Factor A: A Systematic Review and Meta-Analysis. Int J Basic Clin Pharmacol 2019;8:2354. [Crossref]

28. Zhu X, Wu S, Dahut WL, Parikh CR. Risks of Proteinuria and Hypertension with Bevacizumab, An Antibody Against Vascular Endothelial Growth Factor: Systematic Review and Meta-Analysis. Am J Kidney Dis 2007;49:186-93. [Crossref] 


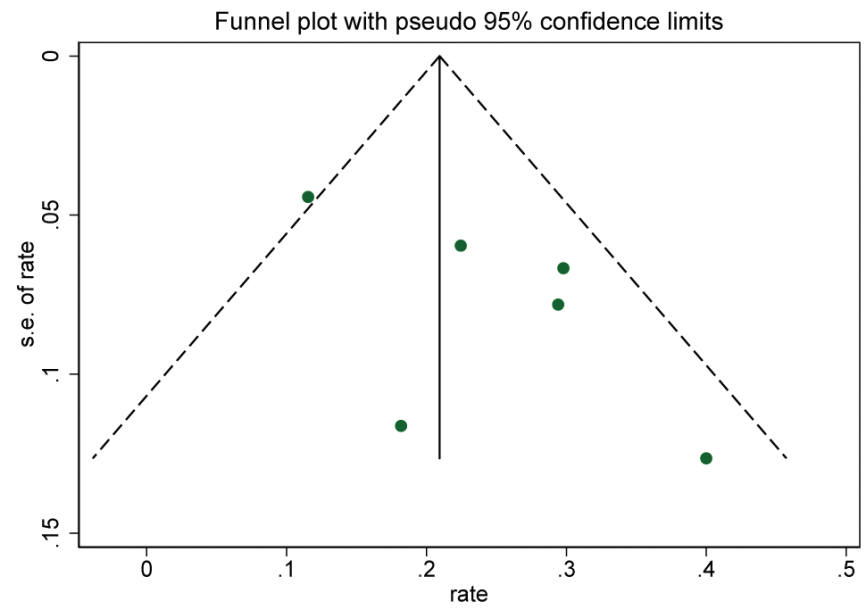

FIG. S1. The funnel plot of the risk of bias.

SE: standard error
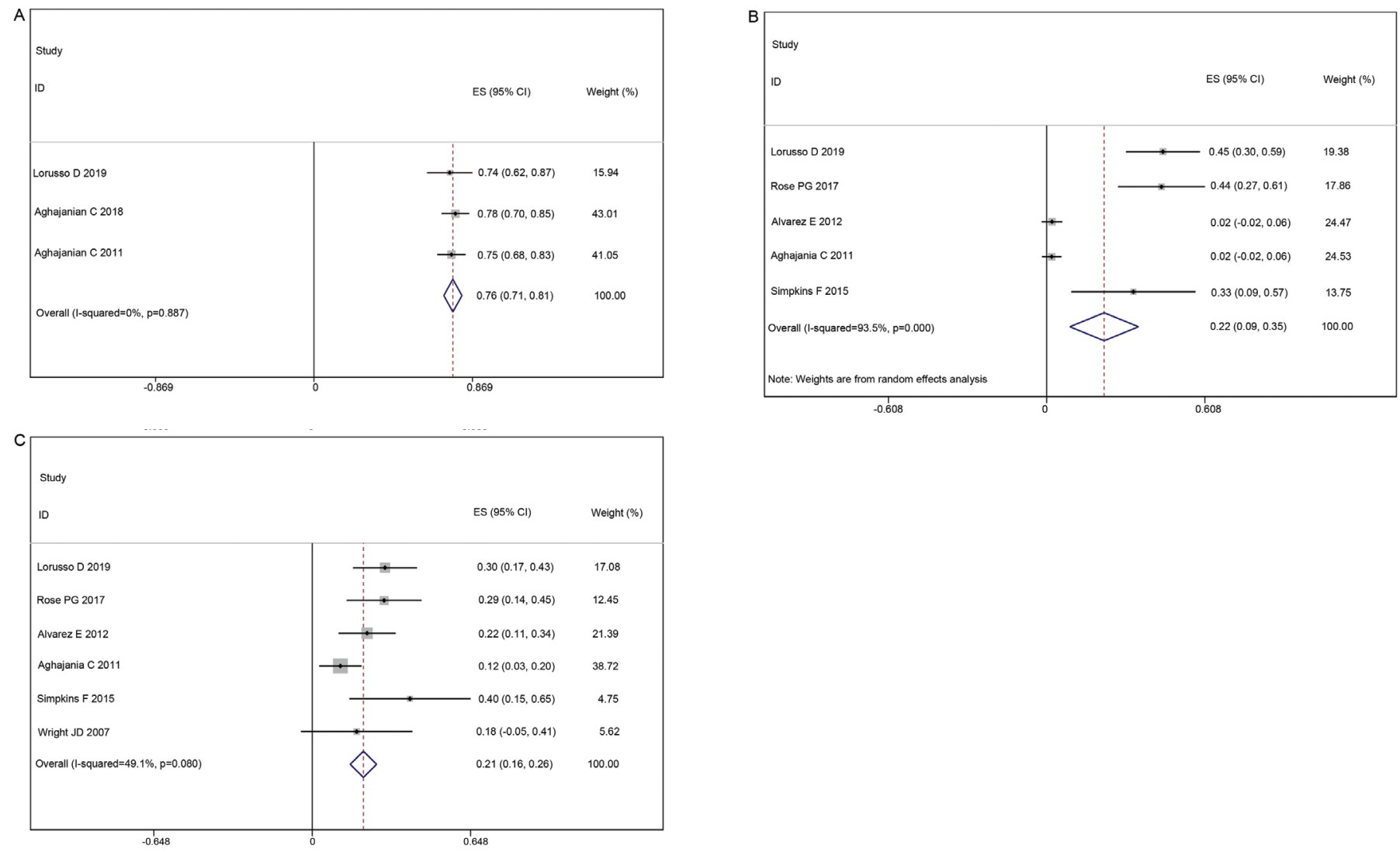

FIG. S2. Pooled analysis of the ORR (A), CRR (B), and PRR (C) in endometrial cancer patients treated with bevacizumab-combined chemotherapy. ORR: overall response rate, CRR: complete response rate, PRR: partial response rate. Cl: confidence interval, ES: effect size 

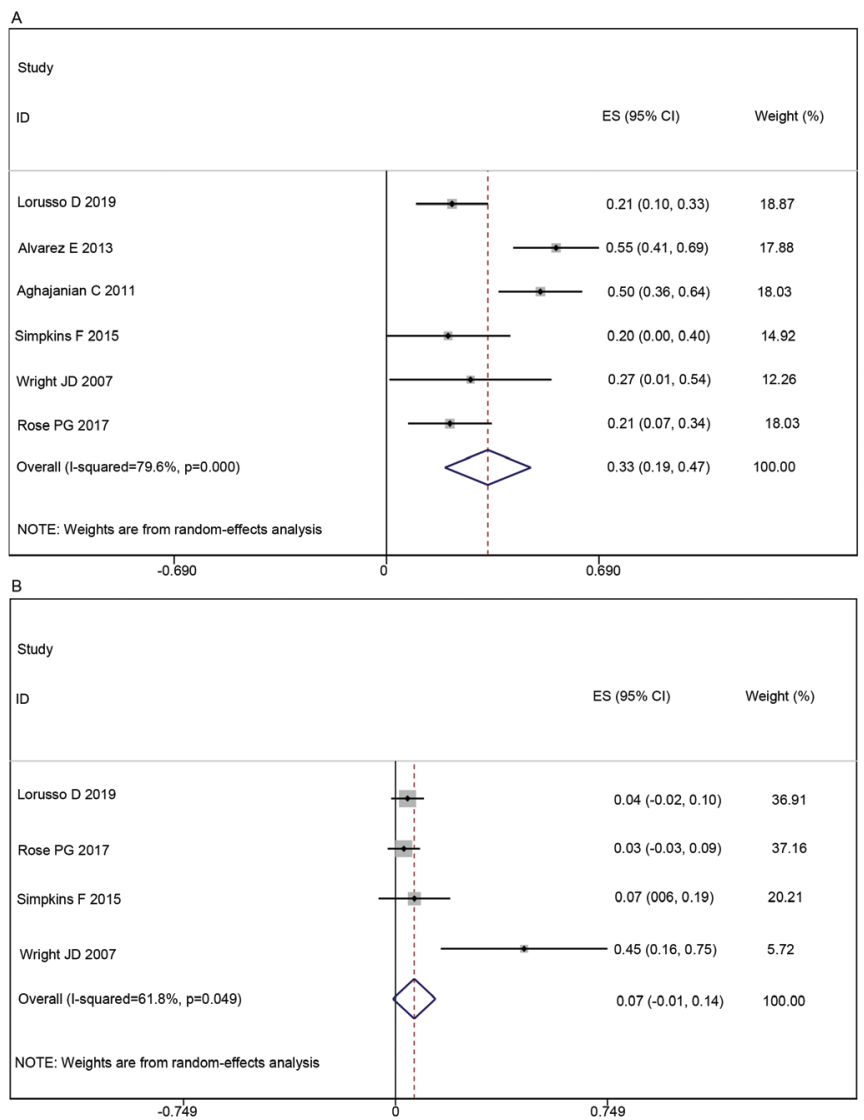

FIG. S3. Pooled analysis of the stable disease $(A)$ and tumor progression (B) in endometrial cancer patients treated with bevacizumab-combined chemotherapy.

$\mathrm{Cl}$ : confidence interval, ES: effect size
A

Study

ID

ES $(95 \% \mathrm{Cl}) \quad$ Weight $(\%)$

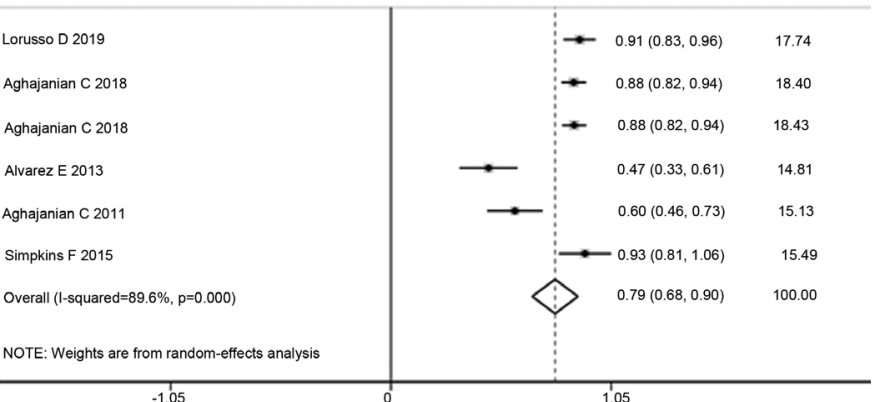

B

Study

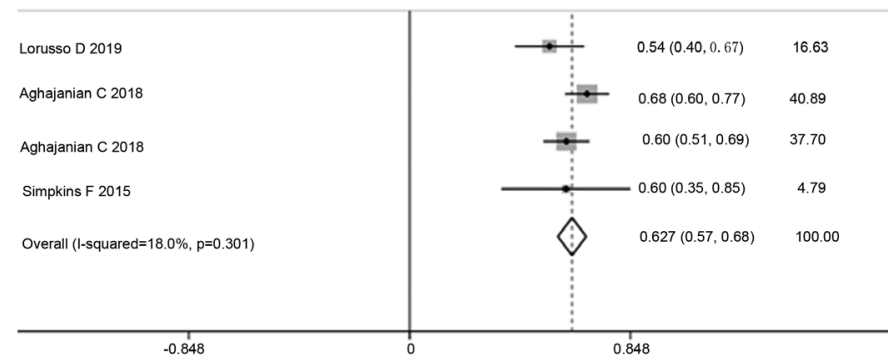

FIG. S4. Pooled analysis of the non-progression of disease at $6(A)$ and 12 months (B) in endometrial cancer patients treated with bevacizumab-combined chemotherapy.

$\mathrm{Cl}$ : confidence interval, ES: effect size 